\title{
Research Difficulties encountered by Business Administration students of College of Management and Business Technology
}

\author{
Ma. Germina Esquivel - Santos
}

Ph.D., College of Management and Business Technology, Nueva Ecija University of Science and Technology, Cabanatuan City, Nueva Ecija, Philippines

\begin{abstract}
This study determined the Research Difficulties encountered by selected Business Administration students while doing their Research study. The study is Descriptive in nature. Survey questionnaire and Convenience sampling were utilized in data gathering. For the Data treatment and analysis, frequency count, percentages and weighted mean were utilized. The result of the study revealed that majority of the respondents encountered difficulty on Linguistic aspect.
\end{abstract}

Keywords_linguistic; research difficulty; research study.

\section{INTRODUCTION}

Research study is a scholarly work aiming at determining and analyzing a certain situation and practices. It is often done to be used as a basis for discovery, enhancement, anticipation, intervention and recommendations. Every Industry is into research study to keep abreast of the Industry needs and demands regardless of the nature of the organization.

Research Writing is included in the Tertiary Curriculum to enhance students' research capabilities and to prepare them for the Industry needs in the future. The task is a significant and tedious one. Researchers should be cautious and diligent in order to come up with the right conclusion and output. This is not easy for there are a lot of difficulties often encountered by researchers that somehow hindered the completion of the task. As mentioned by Alsharif, Nordin and Ismail (2013) students experience challenges during the research process. Hence, a Research study was conducted in order to determine the Research Difficulties encountered by Business Administration students. As stated by Bocar (2013) since Research Writing is one of the academic requirements students and professors have no choice but to deal with it. The likelihood of Research study being completed will be greater if Research Professors will be of help to the students in dealing with the Research difficulties encountered.

\section{OBJECTIVES OF THE STUDY}

1. To determine the difficulties encountered by Business Administration students in terms of:

1.1 cooperation of respondents;

1.2 time management;

1.3 linguistic aspect;

1.4 financial concerns; and

1.5 stress matter.

\section{METHODOLOGY}

The study is Descriptive in nature since its focus was determining the Research Difficulties encountered by selected Business Administration students. The instruments utilized were questionnaire and convenience sampling. A total of 100 4th year Business Administration students were the respondents. For the Data treatment and analysis, frequency count, percentages and weighted mean were utilized.

\section{RESULTS AND DISCUSSION}

\section{Research Difficulties}

1.1 Cooperation of Respondents 
Table 1 As to Cooperation of the Respondents

\begin{tabular}{|l|l|l|}
\hline & Weighted Mean & Verbal Interpretation \\
\hline Researchers had difficulty in terms of... & & \\
\hline 1. availability and schedule of respondents. & 2.55 & often \\
\hline 2. accuracy of responses/data gathered. & 2.51 & often \\
\hline 3. approachability of respondents. & 2.53 & often \\
\hline 4. knowledgeability of respondents on the topic. & 2.37 & sometimes \\
\hline 5. openness and cooperation of respondents. & 2.50 & sometimes \\
\hline 6. comprehensibility of respondents on the prepared questionnaire. & 2.64 & often \\
\hline General Weighted Mean & $\mathbf{2 . 5 2}$ & often \\
\hline
\end{tabular}

Majority of the respondents encountered Research Difficulty on the cooperation of respondents in terms of "comprehensibility of respondents on the prepared questionnaire." This implies that most of the time respondents simply comply with answering the questionnaire without giving much thought on their responses. As mentioned by Ales, 2007 Research data collection that involves human subjects is dependent upon either voluntary or involuntary participation of persons.

\subsection{Time Management}

Table 2 As to Time Management

\begin{tabular}{|l|l|l|}
\hline & Weighted Mean & Verbal Interpretation \\
\hline Researchers had difficulty in terms of... & & \\
\hline 1. managing distractions while conducting the research study. & $\mathbf{2 . 8 1}$ & often \\
\hline 2. prioritizing tasks & $\mathbf{2 . 5 7}$ & often \\
\hline 3. sufficiency of time allotted for conducting the research. & $\mathbf{2 . 8 7}$ & often \\
\hline 4. flexibility in multi-tasking of school requirements. & $\mathbf{2 . 8 6}$ & often \\
\hline 5. adherence on the method of conducting a research study. & $\mathbf{2 . 6 7}$ & often \\
\hline General Weighted Mean & $\mathbf{2 . 7 6}$ & often \\
\hline
\end{tabular}

On Time Management majority of the respondents encountered Research Difficulty in terms of "sufficiency of time allotted for conducting the research". This implies that respondents viewed time given to do research as limited.

\subsection{Linguistic Aspect}

Table 3 As to Linguistic Aspect

\begin{tabular}{|l|l|l|}
\hline & Weighted Mean & Verbal Interpretation \\
\hline Researchers had difficulty in terms of... & & \\
\hline 1. correctness in grammar of research manuscript. & $\mathbf{3 . 2 8}$ & always \\
\hline $\begin{array}{l}\text { 2. sufficiency of vocabulary for ease in conducting the } \\
\text { research study. }\end{array}$ & $\mathbf{2 . 9 1}$ & often \\
\hline $\begin{array}{l}\text { 3. punctuation on the research manuscript for better } \\
\text { understanding. }\end{array}$ & $\mathbf{2 . 9 0}$ \\
\hline $\begin{array}{l}\text { 4. spelling in preparing the pertinent documents for the } \\
\text { conduct of research study. }\end{array}$ & $\mathbf{3 . 1 2}$ \\
\hline 5. mastery in writing and conducting research study. & $\mathbf{3 . 0 6}$ & often \\
\hline General Weighted Mean & $\mathbf{3 . 0 5}$ & often \\
\hline
\end{tabular}

Students are often overwhelmed by various activities which made it difficult for them to manage time and be committed. Dombeck and Wells-Moran (2006) claim that time management skills boil down to awareness, organization and commitment. 
As to Linguistic Aspect, majority of the respondents encountered difficulty in terms of "correctness in grammar of research manuscript". This implies that most of the respondents lacked self confidence regarding their writing capabilities which made it difficult for them to finish their research manuscript. Development of skills in research begins in basic education. (Maldia, 2014)

\subsection{Financial Concern}

Table 4 As to Financial Concern

\begin{tabular}{|l|l|l|}
\hline & Weighted Mean & Verbal Interpretation \\
\hline Researchers had difficulty in terms of... & & \\
\hline 1. availability of personal funds for conducting research. & $\mathbf{2 . 9 1}$ & often \\
\hline $\begin{array}{l}\text { 2. concernment on personal savings being used for research } \\
\text { expenses. }\end{array}$ & $\mathbf{2 . 9 7}$ & often \\
\hline 3. costliness of conducting a research study. & $\mathbf{3 . 1 9}$ & often \\
\hline $\begin{array}{l}\text { 4. allotment of budget on the duration of the conduct of } \\
\text { research study. }\end{array}$ & $\mathbf{3 . 1 8}$ & often \\
\hline 5. production cost of research manuscript and output. & $\mathbf{2 . 2 2}$ & sometimes \\
\hline 6. extensibility cost incurred during data gathering. & $\mathbf{3 . 1 5}$ & often \\
\hline General Weighted Mean & $\mathbf{2 . 9 4}$ & often \\
\hline
\end{tabular}

"Costliness of conducting a research study" as Financial Concern was encountered as Research Difficulty of majority of the respondents. This shows that, most of the respondents had research funding concerns for it is not one time task as the name implies "re-search", it is diligent research. As stated by Mendez, (2010) Research takes repetition and repetition to find the answers.

\subsection{Stress Matter}

Table 5 As to Stress Matter

\begin{tabular}{|l|l|l|}
\hline & Weighted Mean & Verbal Interpretation \\
\hline Researchers had difficulty in terms of... & & \\
\hline 1. collaboration among members. & $\mathbf{2 . 7 3}$ & often \\
\hline 2. appropriateness of data gathering instruments and methodologies. & $\mathbf{2 . 8 7}$ & often \\
\hline $\begin{array}{l}\text { 3. confidence of researcher in conducting and completing the research } \\
\text { study. }\end{array}$ & $\mathbf{2 . 8 2}$ often \\
\hline 4. revision and finalization of research manuscript and output. & $\mathbf{2 . 8 7}$ & often \\
\hline $\begin{array}{l}\text { 5. anxiousness of researcher to meet research and other academic } \\
\text { requirement deadlines. }\end{array}$ & $\mathbf{3 . 0 2}$ & often \\
\hline 6. identification of researchable topics and construction of research title. & $\mathbf{2 . 9 5}$ & often \\
\hline $\begin{array}{l}\text { 7. contribution and participation of researchers on the analysis and } \\
\text { interpretation of data. }\end{array}$ & $\mathbf{2 . 9 0}$ & often \\
\hline General Weighted Mean & $\mathbf{2 . 8 8}$ & often \\
\hline
\end{tabular}

As to Stress matter," anxiousness of researcher to meet research and other academic requirement deadlines" was encountered as Research Difficulty of majority of the respondents. This implies that respondents were not used to handling several activities at a time that might be resulting to difficulty and stress experiences. The University of
Cincinnati (2001) as sited by Bocar (2014) observes that undiagnosed and untreated major emotional issues such as loss, depression, and anxiety may cause students to feel inadequate or result in serious academic difficulties and failure. 


\section{Summary Table}

\begin{tabular}{|c|c|c|}
\hline & General Weighted Mean & Verbal Interpretation \\
\hline \multicolumn{3}{|c|}{ Researchers had difficulty in terms of... } \\
\hline 1. cooperation of respondents & 2.52 & often \\
\hline 2. time management & 2.76 & often \\
\hline 3. linguistic aspect & 3.05 & often \\
\hline 4. financial concern & 2.94 & often \\
\hline 5. stress matter & 2.88 & often \\
\hline Grand Weighted Mean & 2.83 & often \\
\hline
\end{tabular}

In totality among the Factors contributing to Research Difficulties, linguistic aspect is viewed by the respondents as the most common research difficulty encountered. The Development and progress of research writing depends greatly on the writing skills of the researchers. Students do research in their level of understanding, investigation, experimentation, discovery with explanation using simple theory in the form of telling research. (Maldia, 2014)

\section{CONCLUSION}

As viewed on the above mentioned results of the study, the researcher concludes that, majority of the respondents encountered research difficulties regarding cooperation of their respondents in seriously answering their questionnaire, the limited time allotted to them to conduct the research study, capabilities in writing the research manuscript, cost incurred in the duration of conducting the research study, anxiety in meeting research and other academic deadlines. In totality the major research difficulty encountered is in terms of Linguistic aspect which is writing the research manuscript.

\section{RECOMMENDATIONS}

1. Researchers aside from inclusion of a cover letter to their questionnaire should also orient respondents about the nature and objectives of the research study and should give them ample time to answer the questionnaire.

2. The research subject should be offered in two semesters to give the students ample time to conduct their research study and be able to come up with quality output. Research 1 should cover the theories of a Research study, writing of chapters 1 to 3 and questionnaire. Research 2 should be for data gathering, research manuscript preparation and oral defense.
3. Inclusion of Technical Writing to English subjects since at present it is not part of the Business Administration curriculum. The knowledge and skills obtained will aid students in conducting a research study.

4. Prioritize relevant and on campus Research Topics, it will not only benefit the University but it will also help students to minimize the cost of conducting the research study.

5. Regular consultation among subject Professors in order to track students development and activities so there will never be over lapping of academic deadlines.

\section{ACKNOWLEDGEMENTS}

Sincerest gratitude of the researcher to God Almighty for all the opportunities and blessings and to the respondents of this research study for their cooperation and help.

\section{REFERENCES}

[1] Ales, .R R. (2007) Study of Student's Perceptions on a Research Environment Study, N.A.S.P.A Journal Retrieved January 25, 2017

[2] Alsharif, Mohammed H., Nordin, Rosdiadee, and Ismail, Mahamod (2013) Classification, Recent Advances and Research Challenges in Energy Efficient Cellular Networks Retrieved February 14, 2017

[3] Bocar, Anna C. (2013) Difficulties Encountered by the Student-Researchers and the Effects on their Research Output, La Salle University, Ozamiz Retrieved January 25, 2017

[4] Dombeck, M. \& Wells-Moran, J. (2006). Time Management and Organization. Retrieved January 25, 2017

[5] Maldia, Florencia (2014) Teacher's College Journal Retrieved January 25, 2017

[6] Mendez ,F.C. (2010) Updating Challenges into Research Practices, Published Manuscript, University of California, Los AngelesRetrieved February 15, 201 